\title{
Mesothelial Cell
}

National Cancer Institute

\section{Source}

National Cancer Institute. Mesothelial Cell. NCI Thesaurus. Code C33104.

A flat cell of mesenchymal orig in that forms the superficial layer of the serosal membranes lining the body cavities of the abdomen and thorax. 